Alexander N. Lavrentiev

Doctor of Arts, Professor,

Vice-rector for scientific and international work of the Stroganov Moscow State Academy

of Industrial and Applied Arts

e-mail: strog-nauka2011@yandex.ru

Moscow, Russia

ORCID0000-0001-6986-1229

Researcher ID W-1687-2017

\title{
AVANT-GARDE DIALOGUES
}

Summary: The article is dedicated to comparative analysis of spatial constructions created by the Russian Avant-Garde Artist Alexander Rodchenko and the fa mous kinetic European and American artist Alexander Calder in the first half of the 20-th century. For both artists technology played the decisive role in constructing ists technology played the decisive role in constructing spatial objects, both of them used line as a basic expressive element. Still there is a certain difference stressed by thucturat and constructive qualities of spatial objects,

There exist certain parallels and comparisons in the history of the Modern Art sculpture. As a whole it can be regarded as an international substance. Local works and figures sometimes help to understand global processes. Especially interesting is the period at the origin of abstract sculpture and the creation of a new branch, which in Russia in the 1920-s got the name of "constructions", or "spatial constructions".

Alexander Rodchenko (1891-1956), the Russian Avant-garde painter, designer and photographer is well known as the creator of the three original cycles of spatial constructions in 1918-1921. Even more, while creating these works, he developed the title. From works which he called in the catalogue of the 10-th State exhibition in Moscow as "White Non-Objective Sculptures" he came to free suspended mobiles made of concentric elements which were entitled "Constructions". His so-called "sculptures" were made of cardboard geometric details connected by hinges. The title "Sculpture" had to stress two aspects. First those were 3D objec ent sides. Second, the forms were attache the basement, like in most portraits or figure etudes. The free-suspended objects did not have while Calder was more intending to represent emotion and movement

Rodchenko and Calder belong to the common abstract artistic trend in 20th century sculpture. But their works served as the basis for the two different traditions: minimalist conceptual and geometric art of Donuld Judd on one side and spontaneous metric art of Donuld Tinguely on the other.

Keywords: Alexander Rodchenko, Russian Avant-garde, design, Alexander Calder, constructivism.

any links with the traditional understanding of sculpture. They were representing some kind of geo- metrical and technological principles, ideas of structure in a very general sense rathe than interpreting some natural forms or dealing with ethical were analytical formulas.

While working over these objects Rodchenko came to a paradoxical conclusion that surface (flat material) is more spatial than the volume. He wanted to underline the contrast between the narrow border of the form (in fact a line) and the surface as a huge flat and even area. The con trast between the sharp edge and the nuance is the tonal gradient of the surface. From his point of view this contrast gave stronger feeling of space than the massive volumetrically forms. In fact, a number of artists started to use flat material - cardboard, plywood, metal and later plexiglas as a material of spatial compositions due to this effect.

Graphics and elements mostly associated with graphics became the material of spatial forms.

Alexander Calder could come to similar conclusions after his series of animals or human figures made of wire. The line as a usual graphic too

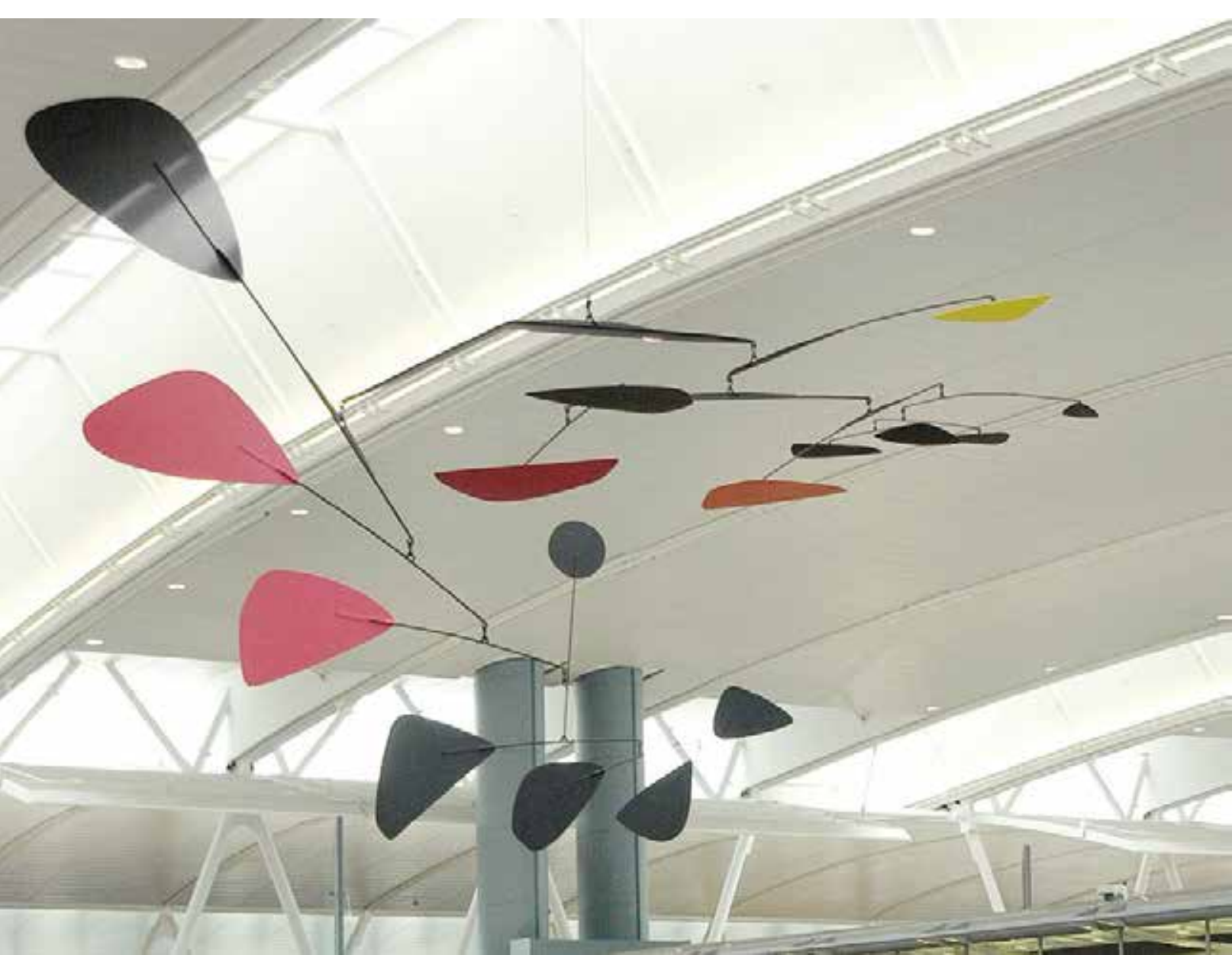

\section{l. 1. Alexander Calder}

was used as a material of a sculpture in 1926 1928. But even in the abstract sculptures like the "Universe" of 1931, or balancing compositions of 930 where the forms bent from wires create an absolutely on the territory of fine art. Due to some imperfections in finished work, that stresses the handmade quality of the object. In his famous "Circus" we can see how inventively these very schematic contours suddenly reflect characteristic features of motion of acrobats, magicians, animal tamers and animals themselves.

In Alfred Barr's book "Cubism and Abstract Art" two works by Alexander Calder were published the mobile and the wire construction. Alfred Barr mentioned him as "sculptor and constructivist". The same characteristic was given to Alexander Rodchenko: "painter, constructivist, typographer, photographer".

The book was published in the conjunction with the exhib tion with the same title "Cubism and Abstract Art" at the Museum of Modern Art in New York in 1936. It was first really sculpture, constructions, photography, architecture, industral art, theatre, film, posters, typography.
The whole book is an interesting justification of abstraction in Art as a new tradition of the 20 century. In order to prove it Barr construct ed diagram showing the influences and crossroads of major artistic trends of the late 19-th and early 20 -th centuries that were placed on the cover of his book. Abstraction started to characterize the contemporary way of seeing, thinking and quasi-scientific research in Art. In Alfred Bar's concept constructivism has a wide specter of artists and in cludes a lot of events, which we traditionally place outside the movement.

Works of Calder were photographed for the book directly in the artist's studio. Rodchenko's works were repres graphic design and some real graphic pieces donated to Barr during his visit to Moscow in 1928. "Malevich grew to be the center of a large circle of younger artists some of whom, under the leadership of Alexander Rodchenko, formed a schismatic group calling themselves the Non-Objectivists"

2. Barr, Alfred. 1936. Cubism and Abstract Art, New York, p.126 


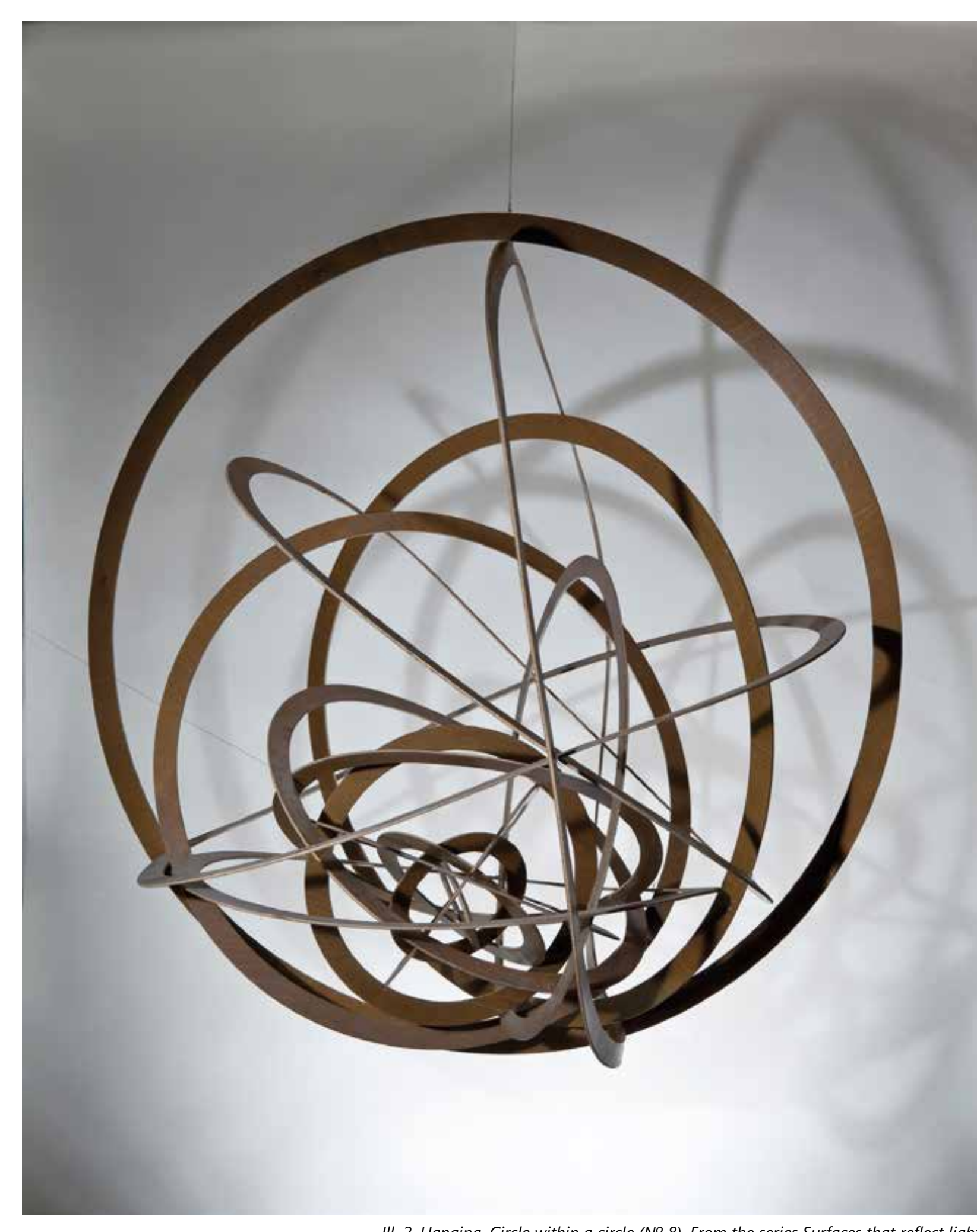

III. 2. Hanging. Circle within a circle (№ 8). From the series Surfaces that reflect light
1920-1921 Reconstruction by A.N. Lavrentiev, 1991, based on sketches by A.M. Rodchenko, 1920-192

Barr calls Rodchenko's series of line-construc- it was not a relief, it was not a solid object as well. tions "the first of their kind".

It was an airy structure, which used quite a rare

The reason why Barr included into his book Rodchenko's spatial construction no.14 (quite a rare object, linking the artist's linear concept with works on paper, paintings and the 3D sculptures) was its unusual tectonics. It was not a sculpture, neither principl of cantilever bhance. The only existing Barr and included into his book. This object was incomparable with other objects in the book or in the exhibition at the Museum of Modern Art. The second construction mentioned by Barr - was the circle within the circle as the first free sus- pended mobile.

But both of Rodchenko pieces correspond well to the suspension and balance compositions by Alx ander Calder.

For Barr the most precious was this early period of "pure Constructivism", proceeding the "more practical activities" 3 of Rodchenko and his friends from the circle of constructivists who designed the atre sets, kiosks, posters and typography.

According to Barr's principal division and clas sification of abstract art there are two main flows: intellectual, concerned with structure and emotional, concerned with expression. The same two flows can be found in the constructivist trends. Rod chenko would represent the more rational pole of construction, while Calder - more intuitive. They balance each other, forming the strange "constructivist swings".

Barr seems to understand the nature of this link between Rodchenko and Calder. In a passage from the same book dedicated to Calder he cannot miss Rodchenko and Gabo as reference points.

Calder, under the joint influence of Mondrian and Gabo, turned his back on the popular success of his wire portraits to experiment with mobile constructions built of wire, iron pipe and metal. Many of the mobiles were composed of objects hung by strings or supported by flexible wires. Others were driven by motors. They display an ingenuity and visual humor quite different from the kinetic constructions which Gabo designed as early as 1922 or Rodchenko's hanging constructions of 1920. Recently Calder has deserted geometrical shapes for irregular quasi-organic forms.

Helion was also a devoted follower of Mondrian but has gradually broken away from flat squares and straight lines to curved, slightly modelled forms without, however, sacrificing the purity of his earlier style" ${ }^{4}$

Alfred Barr's publication could serve for Rodchenko as a source-book about the Modernist trends in the World Art. And he could see there a couple of Calder's works.

Calder was as part abstract dada as movable Arp.

Rodchenko was 7 years older than Calder. It is not a big difference, but still they belong to different stages of Modernism. Rodchenko acted at the 3. ibid, p.133
4. ibid, p.197 moment of breaking with the tradition of realism. Calder came into action at the moment when abstraction was already proclaimed and he was free

to move in any direction - towards expressive abstraction or metaphorical associations, design or architecture.

In comparison with Rodchenko Calder had realy technical education as mechanical engineer from Sevens Institute of Technology - (1919, when Rodchenko already announced his Non-objective ap proach) and worked as an engineer.

Rodchenko had only artistic uncompleted education from the Kazan Art School. His technological skills came from being dentist's apprentice and collecting all the construction manuals. He liked order and all of his instruments were placed on a panel attached to the wall in his darkroom and hanging vertically. There was a hand drill here, pliers, pincers for stretching the canvas, wood borer, hammer, snips (scissors for metal), centimeter and etc. Perhaps Rodchenko and Calder could use almost identical type of a drill - they both needed holes for assembling.

There is another book where Calder and Rodchenko come upon each other. It is a monograph by a Russian contemporary kinetic artist and architect Viacheslav Koleichuk called "Kinetism". In a wider sense kinetic art is an absolutely new field of artistic creation, which was foreseen and es tablished due to the activity of Calder and Rodchenko. They both put action into their works and started to use motion as integral part of the artistic imagery.

Kinetic compositions using natural engines are rather different. Let us remember the monument to Columbus designed by Melnikov or mobiles by Calder, using the motion of the air" ${ }^{5}$, - writes Koleichuk.

Of course, Rodchenko and Calder nowadays can be placed together as outstanding artists, as contemporaries, as those who defined the contemporary art.

But somehow their biographies link. Living in Paris, Calder knew Man Ray and Leger. Rodchenko met them as well three years earlier in 1925 working for the Soviet section of the International exhibition of Decorative Arts.

There is a note that heads to the advertising agency in Philadelphia an admirer of futurism, Leo 
Lionni in the 1940-s commissioned Calder among other young artists. Lionni's greatest impression of his childhood was Chagall's picture of a Fiddler in his family house in Amsterdam. Through Chagall we can reach the Russian avant-garde art and the whole situation in Russia with strong constructivist trends. Rodchenko and Chagall could easily meet in Moscow in 1917 when Rodchenko was a secretary of the Young Federation of the Painter's Trade-union.

Rodchenko and Calder have positions on different sides of the constructivist kinetic see-saw. Rodchenko is fully analytical. His goal is disselec- tion and representation of the details of the mechanism. Calder is more expressive. He puts life into the mechanism. Calder's works represent the tensions of space, which is not homogenius and has points of concentration of energy. His sculptures often have needle-point edges that look like a stroke of a lightning...

There exists a caricature on Rodchenko made by his wife Varvara Stepanova in 1922. Rodchenko is wearing his famous constructivist outfit and holding a line in his hand as his main tool, which also resembles Zeus with a lightning...

\section{REFERENCES:}

1. Barr, Alfred. 1936. Cubism and Abstract Art, New York, p.126 (in English)

2. Koleichuk, V. 1994. Kinetism, Moscow, p.28 (in Russian)

3. Burganova, M. 2013. "Expirience of minimalism", Art Literature Scientific and Analytic Journal Burganov House. The Space of Culture, vol.9, no.1, pp. 15-31 (in Russian)

4. Lisina, E.A., Kurasov, S.V.2021. "Le Corbusier's urban development ideas in contemporary urban discussion", Decorative art and subject-spatial environment. MGHPA Bulletin, no. 4, Part 1 (in Russian)

5. Lavrentiev, A.N. 2021. "Vyacheslav Koleichuk as the Engine of the Russian Kinetic Art. Imaginary dialogue at the exhibition", Art Literature Scientific and Analytic Journal Burganov House. The Space of Culture, vol. 17, no. 1, pp. 95-117. DOI:10.36340/2071-6818-2021-171-95-117 (in English, in Russian)

6. Gluibizzi, A. 2021. Art and Design in 1960s New York. London, UK; New York, NY, USA: Anthem Press. DOI:10.2307/j.ctv1gbrrk9 (in English)
7. Topper, D., \& Holloway, J. 1980. Interrelationships between the Visual Arts, Science and Technology: A Bibliography, Leonardo, 13(1), 29-33. DOI:10.2307/1577916 (in English)

8. Zinman, G. 2020. Making Images Move: Handmade Cinema and the Other Arts. Oakland, California: University of California Press. DOI:10.2307/j.ctvqr1bkx (in English)

9. George F. Flaherty. 2014. "Responsive Eyes: Urban Logistics and Kinetic Environments for the 1968 Mexico City Olympics", Journal of the Society of Architectural Historians, 73(3), 372-397. DOI:10.1525/ jsah.2014.73.3.372 (in English)

10. Galeyev, B. 1991. "Musical-Kinetic Art in the USSR", Leonardo, 24(1), 41-47. DOI:10.2307/1575467 (in English)

11. Applin, J., Spencer, C., \& Tobin, A. (Eds.). 2018. London Art Worlds: Mobile, Contingent, and Ephemeral Networks, 1960-1980. University Park, Pennsylvania: Penn State University Press. DOI:10.5325/j.ctv14gp4cg (in English) 